\title{
Cultivo in vitro de Dendrobium nobile com uso de água de coco no meio de cultura
}

\author{
Jackeline S Soares ${ }^{1}$; Yara BCJ Rosa ${ }^{1}$; Rogério M Suzuki²; Silvana PQ Scalon ${ }^{1}$; Edgard J Rosa Junior ${ }^{1}$ \\ 1UFGD-FCA, Rod. Dourados-Itaum km 12,79804-970 Dourados-MS; jacke.schultz@gmail.com; yararosa@ufgd.edu.br; \\ silvanascalon@ufgd.edu.br; edgardjunior@ufgd.edu.br; ${ }^{2}$ IBt/SP, C. Postal 68041,04045-972 São Paulo-SP; rogeriosuzuki@gmail.com
}

\begin{abstract}
RESUMO
Aágua de coco é um dos componentes orgânicos de baixo custo mais utilizados nos meios de cultura para cultivo in vitro de plantas, mas poucas são as informações sobre seus efeitos em orquídeas, onde esse tipo de propagação é utilizado. Assim, objetivou-se estudar as quantidades de água de coco acrescidas ao meio de cultura quanto aos seus efeitos na germinação e crescimento in vitro de Dendrobium nobile. Foi utilizado o delineamento experimental inteiramente casualizado, com três repetições, e os tratamentos compostos de cinco volumes de água de coco $\left(0 ; 50 ; 100 ; 150\right.$ e $\left.200 \mathrm{~mL} \mathrm{~L}^{-1}\right)$, que foram adicionados ao meio de cultura. Foram utilizadas como material de estudo sementes de $D$. nobile produzidas mediante autopolinização manual. Após a semeadura, as culturas permaneceram por seis meses em sala de crescimento com temperatura e fotoperíodo controlados (12 horas, 1000 lux; $23^{\circ} \mathrm{C} \pm 2$ ) quando as plântulas foram avaliadas. A adição de $200 \mathrm{~mL} \mathrm{~L}^{-1}$ de água de coco ao meio de cultura propiciou os melhores resultados para comprimento, diâmetro e número dos pseudobulbos, número de folhas, número de raízes, comprimento de raízes e massa fresca de $D$. nobile, não influenciando apenas a porcentagem de germinação e o número de plântulas produzidas.
\end{abstract}

Palavras-chave: Orchidaceae, meio de cultura, cultivo in vitro.

\begin{abstract}
In vitro cultivation of Dendrobium nobile using coconut water in the culture medium

Coconut water is one of the inexpensive organic components most utilized in culture media for in vitro cultivation of plants, but there are few informations about its effect in orchids, where this kind of propagation is used. The objective of this research was to study the effects on germination and growing of Dendrobium nobile when coconut water is added to the in vitro culture medium. We used a completely randomized design, with three replications; the treatments consisted of adding five volumes of coconut water $(0,50,100,150$ and $200 \mathrm{~mL} \mathrm{~L}^{-1}$ ) to the culture medium. Seeds of $D$. nobile, obtained by manual pollination were used as study material. After sowing, the cultures stayed for six months in a growth chamber with controlled temperature and photoperiod ( 12 hours $/ 1000 \operatorname{lux} ; 23^{\circ} \mathrm{C} \pm 2$ ), when the seedlings were evaluated. The addition of $200 \mathrm{~mL} \mathrm{~L}^{-1}$ of coconut water to the culture medium provided the best results for length diameter and number of pseudobulbs, number of leaves, number of roots, length of roots and fresh weight of $D$. nobile, not influencing only the germination percentage and the number of seedlings produced.
\end{abstract}

Keywords: Orchidaceae, culture medium, in vitro cultivation.

(Recebido para publicação em 21 de novembro de 2011; aceito em 4 de fevereiro de 2013) (Received on November 21, 2011; accepted on February 4, 2013)

$\mathrm{O}$ cultivo in vitro tem propiciado a propagação massal de uma série de espécies de orquídeas em risco de extinção ou de elevado valor comercial (Santos et al., 2006). Os meios assimbióticos para orquidáceas, além de propiciar a germinação, também devem possibilitar o crescimento e muitas vezes o desenvolvimento das espécies cultivadas. A maioria deles são complexos, contendo diversos nutrientes, vitaminas e reguladores de crescimento (Ventura et al., 2002), os quais elevam os custos da propagação.

Para atender às necessidades de cada espécie, mudanças nos meios de cultura para orquídeas têm sido estudadas. Faria et al. (2004) verificaram que a adição de $60 \mathrm{~g} \mathrm{~L}^{-1}$ de sacarose no meio MS (Murashige \& Skoog, 1962) proporcionou maior crescimento e taxa de multiplicação de mudas de D. nobile. Pasqual et al. (2009) constataram a viabilidade de multiplicação in vitro de outra espécie de orquídea, Cattleya lodigesii, com a utilização de meio KC (Knudson, 1946) líquido enriquecido com polpa de banana nanica. Cardoso \& Ono (2011) concluíram que a utilização de $1,0 \mathrm{mg} \mathrm{L}^{-1}$ de BAP e de $\mathrm{KNO}_{3}$ e $\mathrm{NH}_{4} \mathrm{NO}_{3}$, na metade da concentração recomendada para o meio MS, é eficiente para a multiplicação da orquídea Brassocattleya. Pasqual et al. (2011) verificaram que a adição de silício em meio MS propiciou ausência de deformações foliares em plântulas de orquídeas. Entretanto, é importante reduzir os custos dos meios de cultura.

Visando a facilidade de formula- ção, baixo custo e acessibilidade dos componentes, Campos (2002) propôs um meio alternativo, no qual a maioria das espécies de orquídeas germina e cresce. Para redução dos custos, estudos com produtos orgânicos (água de coco, banana, mamão, milho) adicionados aos meios de cultura convencionais foram realizados (Martínez \& García, 2007; Araújo et al., 2006b; Vieira et al., 2009; Campos, 2010). Esses produtos orgânicos são também fontes de aminoácidos, vitaminas, sais minerais e reguladores de crescimento, que são os componentes mais onerosos dos meios de cultura, segundo Araújo et al. (2006a).

Dentre eles, a água de coco começou a ser adicionada em meios nutritivos há mais de meio século por Overbeek et al. (1941). Segundo Aragão et al. (2001), 
a água de coco, que é o endosperma de Cocus nucifera, apresenta em sua composição básica $93 \%$ de água, $5 \%$ de açúcares, além de proteínas, vitaminas e sais minerais, grau brix igual a 7,0 $\left(21^{\circ} \mathrm{C}\right)$ e $\mathrm{pH}$ em água igual a 4,8. Cada $100 \mathrm{~mL}$ de água de coco contém 4,4 g de glicose; 0,37 mg de proteínas: $6,2 \mathrm{mg}$ de fósforo; $175 \mathrm{mg}$ de potássio; $17,5 \mathrm{mg}$ de cálcio; 8,5 mg de magnésio; 10,5 mg de sódio; 0,06 mg de ferro e $57 \mathrm{mg}$ de vitamina $\mathrm{C}$.

A concentração de água de coco utilizada na composição dos meios de cultura é de 3 a 15\% para um grande número de espécies vegetais cultivadas in vitro. Ela é utilizada para estimular o crescimento de calos, aumentar a germinação assimbiótica, formar embriões somáticos, induzir a divisão de grãos de pólen e o desenvolvimento de embriões imaturos (Caldas et al., 1998).

Embora seja o componente orgânico mais utilizado no enriquecimento de meios de cultura, seus efeitos em relação à promoção da germinação, crescimento e desenvolvimento in vitro de orquídeas necessitam ser mais estudados uma vez que é constituída por diversas classes de hormônios vegetais tais como ácido indol acético, ácido indol butírico, ácido abcísico, ácido giberélico, zeatina, benzil adenina, ácido naftalenoacético e ácido diclorofenoxiacético (Ma et al., 2008), os quais influenciam as diferentes fases do desenvolvimento vegetal. $\mathrm{O}$ efeito benéfico da adição de água de coco pode ser explicado pelos elevados teores de glicose, frutose e sais minerais, além de hormônios vegetais, necessários ao processo de formação e desenvolvimento das plântulas (Nunes et al., 2008). Além disso, deve-se considerar também o status nutricional e hormonal endógeno de cada material de estudo, ressaltando a necessidade de estudos específicos em relação à espécie vegetal de interesse bem como ao propósito de sua utilização na promoção quer da germinação, organogênese ou embriogênese in vitro.

Objetivou-se estudar a quantidade de água de coco acrescida ao meio de cultura de Campos (2002) quanto aos seus efeitos na germinação e crescimento in vitro de Dendrobium nobile.

\section{MATERIAL E MÉTODOS}

$\mathrm{O}$ experimento foi realizado no laboratório de cultivo in vitro da $\mathrm{Fa}$ culdade de Ciências Agrárias (FCA) da Universidade Federal da Grande Dourados (UFGD). O delineamento experimental foi inteiramente casualizado, sendo os tratamentos compostos de cinco volumes de água de coco (0; $50 ; 100 ; 150$ e $200 \mathrm{~mL} \mathrm{~L}^{-1}$ ), que foram adicionados ao meio de cultura e três repetições. A parcela experimental foi composta de um frasco de meio de cultura. Foram utilizadas como material de estudo sementes de Dendrobium nobile produzidas mediante autopolinização manual, cedidas pelo Orquidário da FCA. Cápsulas maduras foram coletadas e as sementes provenientes destas, foram retiradas, homogeneizadas, pesadas e, 0,005 g submetidas ao teste de tetrazólio para determinação da viabilidade. Após a confirmação da viabilidade procedeu-se à semeadura in vitro.

Utilizou-se o meio de cultura proposto por Campos (2002), modificado pela utilização de $70 \mathrm{~g}$ de tomate sem casca e sementes, $50 \mathrm{~g}$ de banana nanica sem casca, $3 \mathrm{~mL}$ de adubo NPK na formulação 10-10-10, $17 \mathrm{~g}$ de ágar bacteriológico, $25 \mathrm{~g}$ de açúcar cristal, 3 g de carvão ativado, água de coco nos volumes $0 ; 50 ; 100 ; 150$ e $200 \mathrm{~mL} \mathrm{~L}^{-1}$ e água destilada para completar um litro. Optou-se pela utilização deste meio alternativo pela facilidade de aquisição de seus componentes e pelo baixo custo, o que o torna acessível aos produtores.

Após homogeneização no liquidificador, o $\mathrm{pH}$ foi ajustado para 5,0 com $\mathrm{KOH}$ e $80 \mathrm{~mL}$ do meio de cultura foi transferido para frascos de $600 \mathrm{~mL}$ providos de tampa metálica, sendo, a seguir, esterilizados em autoclave por 20 minutos a $120^{\circ} \mathrm{C}$ e uma atmosfera de pressão. Em seguida à esterilização e solidificação do meio, os frascos foram transferidos para câmara de fluxo laminar, previamente esterilizada com luz germicida por 30 minutos, para realização da semeadura in vitro.

Cada porção de $10 \mathrm{mg}$ de sementes foi transferida para erlenmeyer e desinfestada por 15 minutos em uma solução composta por $3 \mathrm{~mL}$ de hipoclorito de sódio $(2,5 \%)$ e $6 \mathrm{~mL}$ de água destilada esterilizada em autoclave (Campos, 2002). Decorrido este tempo, a suspensão foi diluída para $50 \mathrm{~mL}$ com água destilada estéril, no interior da câmara de fluxo laminar. Cada frasco recebeu, com a utilização de pipetador automático, $2 \mathrm{~mL}$ da suspensão de sementes (aproximadamente 800 sementes viáveis). Foram utilizados três frascos para cada tratamento.

Após a semeadura os frascos foram tampados e lacrados com filme plástico, sendo acondicionados em sala de crescimento com temperatura média de $23^{\circ} \mathrm{C} \pm 2$ e fotoperíodo de 12 horas, com intensidade luminosa de 1.000 lux, obtida por meio de duas lâmpadas fluorescentes de $40 \mathrm{~W}$ cada.

Decorridos seis meses, foram contabilizadas as plântulas e os protocormos produzidos. A germinação (\%) foi calculada levando-se em conta o número de protocormos e plântulas existentes em relação ao número médio de sementes viáveis inoculado em cada frasco. Já para o número de plântulas foram consideradas apenas as plântulas que apresentassem sistema radicular e parte aérea identificáveis a olho nu. Após a completa remoção do substrato, 26 plântulas de cada frasco, selecionadas aleatoriamente, foram avaliadas quanto à massa fresca, comprimento, diâmetro e número de pseudobulbos, número de folhas, número de raízes e comprimento de raízes.

As variáveis foram submetidas à análise de variância e, em função dos resultados obtidos, foi feita a análise de regressão (Banzato \& Kronka, 1992) com a utilização do SISVAR 5.3 (Ferreira, 2010).

\section{RESULTADOS E DISCUSSÃO}

As concentrações de água de coco adicionadas ao meio de cultura influenciaram todas as variáveis avaliadas, exceto a germinação (\%) e o número de plântulas de $D$. nobile, que apresentaram os valores médios de $53,4 \%$ e 170,9 plântulas.

O número de pseudobulbos aumentou em função das doses de água de coco adicionadas, atingindo valores (calculados) de 2,5 pseudobulbos/plântula com 


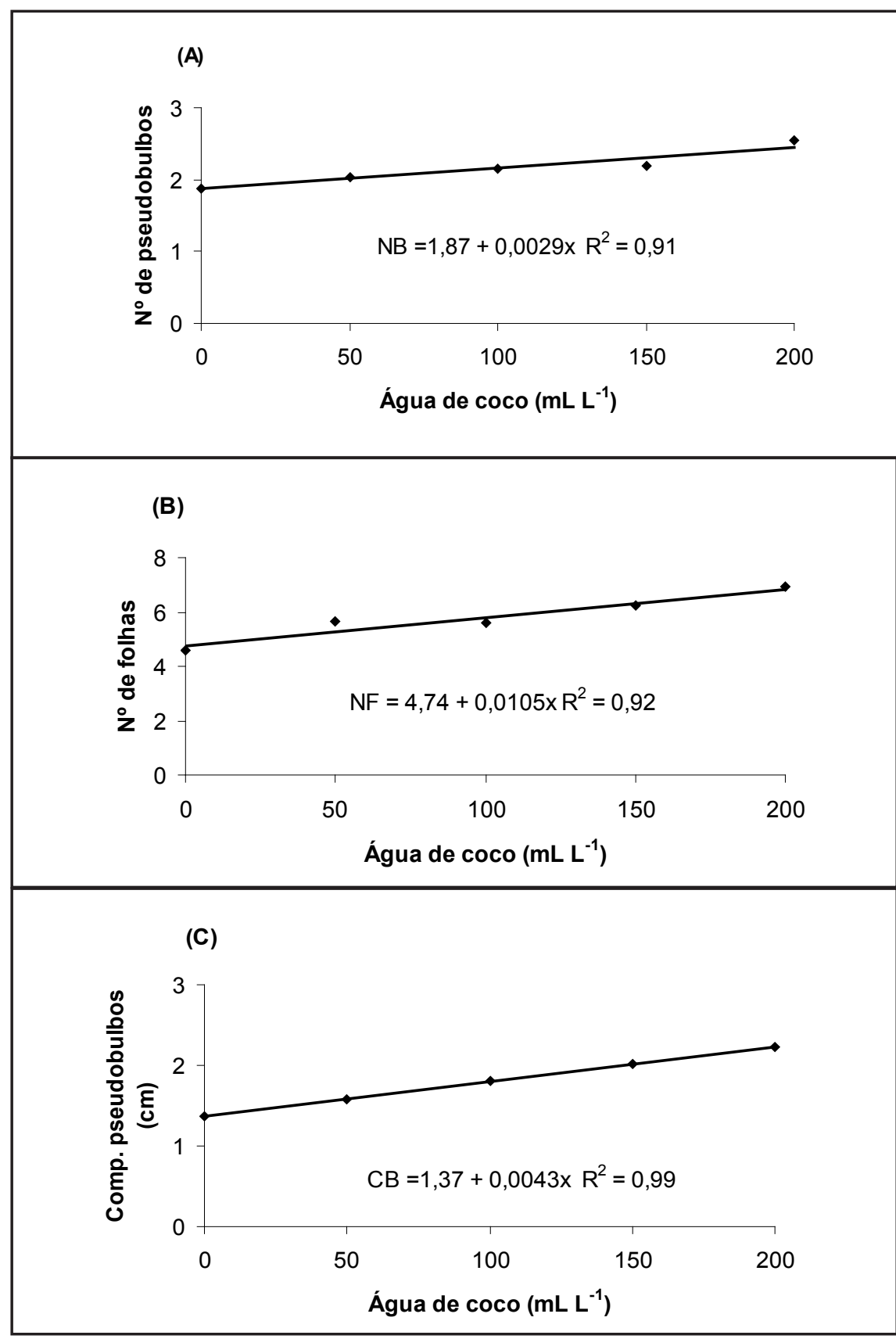

Figura 1. Valores estimados de (A) número pseudobulbos $(\mathrm{NB}),(\mathrm{B})$ número de folhas $(\mathrm{NF})$ e (C) comprimento de pseudobulbos (CB) de plantas de D. nobile, em função dos volumes de água de coco utilizados [estimated values of (A) number of pseudobulbs (NB), (B) number of leaves (NF) and (C) pseudobulbs length (CB), in plants of D. nobile, depending on the volumes of coconut water used]. Dourados, UFGD, 2010.

$200 \mathrm{~mL} \mathrm{~L}^{-1}$ (Figura 1A). Resultados semelhantes foram relatados por Martínez \& García (2007) que obtiveram maior número de pseudobulbos de Stanhopea tigrina (Orchidaceae) com a combinação de $120 \mathrm{~mL} \mathrm{~L}^{-1}$ de água de coco com $100 \mathrm{~g}$ de banana em meio de cultura MS, sendo esta a maior concentração utilizada pelos autores.

$\mathrm{O}$ número de folhas também foi maiores. Já para espécies de outras famílias botânicas, como o pinhão-manso (Jatropha curcas), o aumento das concentrações de água de coco até, o máximo de $250 \mathrm{~mL} \mathrm{~L}^{-1}$, propiciou efeito linear crescente no número de folhas por plântula (Nunes et al., 2008), conforme o presente experimento. As diferenças entre esses dados e de outros experimentos podem ser decorrentes da especificação dos meios de cultura para cada espécie, vez que diferentes combinações de carboidratos, sais minerais, vitaminas e reguladores de crescimento estimulam, ou não, o crescimento de órgãos, tecidos ou células e o desenvolvimento da planta (George et al., 2008). Entretanto, o aumento linear do número de folhas de $D$. nobile pode ser atribuído, principalmente, à cinetina, hormônio existente na água de coco (Ge et al., 2005), que atua na emissão e expansão foliar (Sobieszczuk-Nowicka et al., 2009).

De maneira análoga ao número de folhas e de pseudobulbos, o comprimento dos pseudobulbos também apresentou efeito linear crescente, sendo o maior comprimento calculado $(2,2 \mathrm{~cm})$ obtido com a utilização de $200 \mathrm{~mL} \mathrm{~L}^{-1}$ de água de coco (Figura 1C). Já o diâmetro dos pseudobulbos apresentou resposta quadrática. Os menores valores calculados por meio da derivação da equação $(0,3$ $\mathrm{cm}$ ) foram obtidos com 81,6 mL L-1 e os maiores valores $(0,7 \mathrm{~cm})$ com 200 $\mathrm{mL} \mathrm{L}^{-1}$ de água de coco acrescidos ao meio de cultura (Figura 2A). A ausência de água de coco no meio de cultura reduziu, aproximadamente, 40 e $30 \%$ o comprimento de pseudobulbos e o seu diâmetro, respectivamente, em relação ao uso de $200 \mathrm{~mL} \mathrm{~L}^{-1}$ (Figura 2).

Resultados similares foram obtidos por Simões et al. (1999) que observaram maior crescimento in vitro da parte aérea das espécies de orquídeas Epidendrum sp. e Dendrobium sp. em meio KC contendo $100 \mathrm{~mL} \mathrm{~L}^{-1}$ de água de coco, que foi a maior concentração estudada. Martínez \& García (2007) relataram que os melhores resultados para comprimento da parte aérea das plantas de Stanhopea tigrina (Orchidaceae), foram obtidos com as maiores concentrações, adicionadas ao meio MS, de água de coco $\left(120 \mathrm{~mL} \mathrm{~L}^{-1}\right)$ e de polpa de banana 


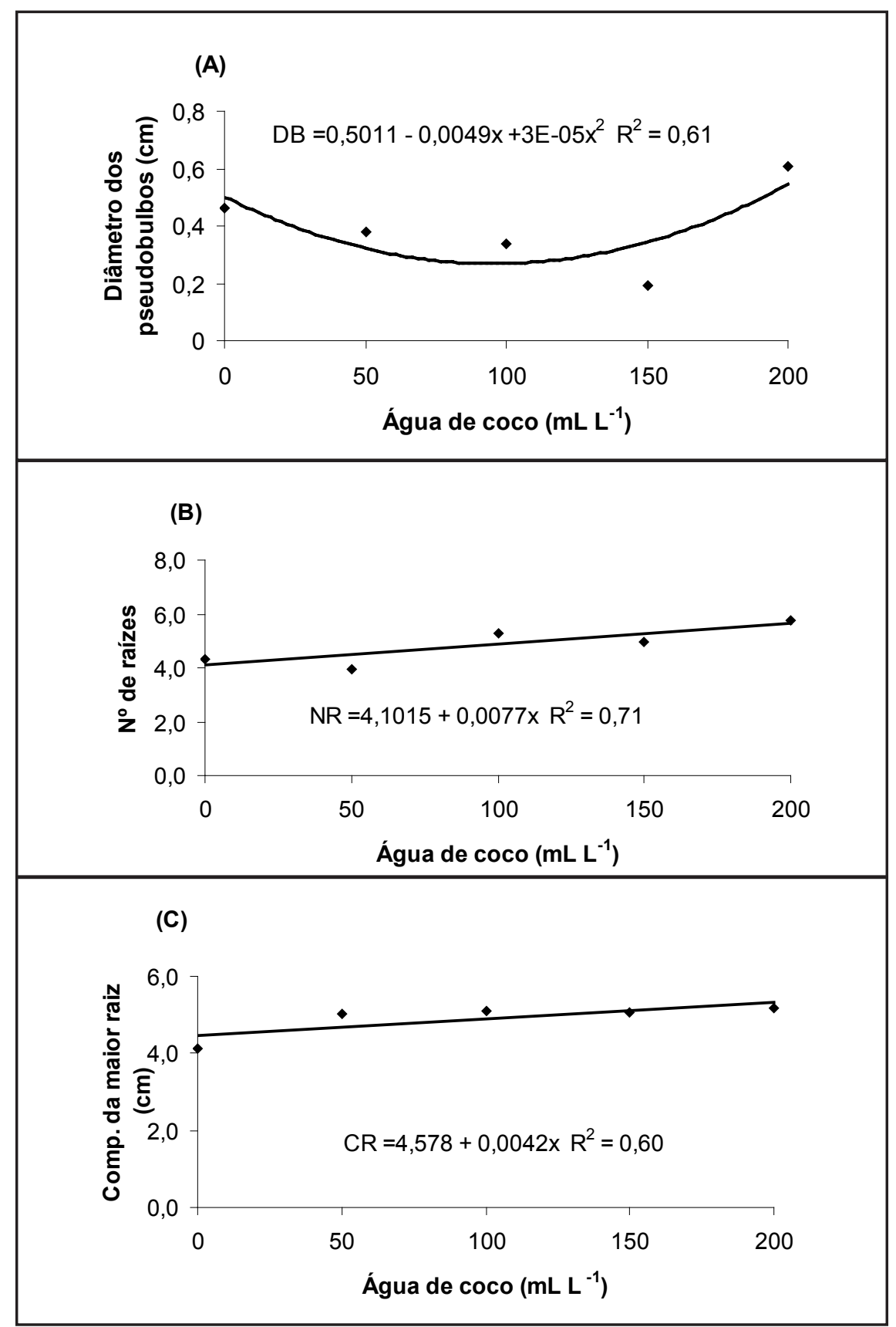

Figura 2. Valores estimados de (A) diâmetro de pseudobulbos (DB), (B) número de raízes (NR) e (C) comprimento de raízes (CR) de plantas de D. nobile, em função dos volumes de água de coco utilizado [estimated values of (A) diameter of pseudobulbs (DB), (B) number of roots (NR) and $(\mathrm{C})$ root length $(\mathrm{CR})$ in plants of $D$. nobile, depending on the volumes of coconut water used]. Dourados, UFGD, 2010.

$\left(100 \mathrm{~g} \mathrm{~L}^{-1}\right)$.

De modo semelhante à parte aérea, a adição de água de coco ao meio de cultura teve efeitos benéficos sobre o sistema radicular. Os maiores números calculados de raízes por plântula $(5,6)$ foram observados com $200 \mathrm{~mL} \mathrm{~L}^{-1}$ de água de coco e os menores $(4,1)$ na sua ausência (Figura 2B). Estes dados são concordantes com aqueles obtidos por Araújo et al. (2006b). Esses autores obtiveram o maior número de raízes (6,5 plântula $\left.{ }^{-1}\right)$ de Cattleya loddigesii 'Grande' x Cattleya loddigesii 'Alba', utilizando o meio de cultura KC, acrescido de $200 \mathrm{~mL} \mathrm{~L}^{-1}$ de água de coco combinado com $100 \mathrm{~g} \mathrm{~L}^{-1}$ de polpa de banana.
Os menores valores para o comprimento de raízes $(4,5 \mathrm{~cm})$ foram registrados na ausência da água de coco (Figura 2C). Foi notado incremento até a maior concentração utilizada $\left(200 \mathrm{~mL} \mathrm{~L}^{-1}\right)$ que propiciou o maior comprimento calculado de raiz $(5,4$ $\mathrm{cm})$. O aumento de água de coco no meio de cultura pode ser considerado benéfico ao comprimento de raiz, conforme também mostraram Vieira et al. (2009) para Cattleya labiata x Cattleya forbesii. Eles observaram os melhores resultados para altura da parte aérea e comprimento de raízes com $100 \mathrm{~mL} \mathrm{~L}^{-1}$ de água de coco (maior concentração utilizada) e, na sua ausência, foram registrados os menores valores destas características. Como citado anteriormente, há muitos hormônios presentes na água de coco, inclusive auxinas, que estão envolvidas em vários processos metabólicos das plantas, principalmente no crescimento. Essas substâncias fazem parte do processo de ramificação tanto da parte aérea (no caso das orquídeas o número de pseudobulbos) quanto das raízes (Berleth et al., 2004). Embora não tenham sido analisados tais compostos, isso poderia justificar o aumento linear no número de pseudobulbos e de raízes.

Comportamento linear crescente também foi observado para a massa fresca da parte aérea de $D$. nobile em relação aos volumes de água de coco, sendo os maiores valores $(0,5 \mathrm{~g})$ propiciados com $200 \mathrm{~mL} \mathrm{~L}^{-1}$ de água de coco (Figura 3). Araújo et al. (2006b) também registraram maiores valores para massa fresca de Cattleya loddigesii 'Grande'x Cattleya loddigesii 'Alba' com o maior volume de água de coco estudado (200 $\mathrm{mL} \mathrm{L}^{-1}$ ) combinados com $100 \mathrm{~g} \mathrm{~L}^{-1} \mathrm{de}$ polpa de banana. Acréscimos de $200 \%$ em massa fresca de plântulas de Cattleya labiata x Cattleya forbesii também foram relatados por Vieira et al. (2009), utilizando $100 \mathrm{~mL} \mathrm{~L}^{-1}$ de água de coco e $100 \mathrm{~g} \mathrm{~L}^{-1}$ de polpa de banana em meio MS. Incrementos de 55\% em relação à testemunha também foram registrados na produção de massa fresca de Cattleya amethystoglossa por Dronk (2004) com $150 \mathrm{~mL} \mathrm{~L}^{-1}$ de água de coco e $150 \mathrm{~g} \mathrm{~L}^{-1}$ de polpa de banana nanica e no meio de cultura.

Embora a utilização de água de coco 


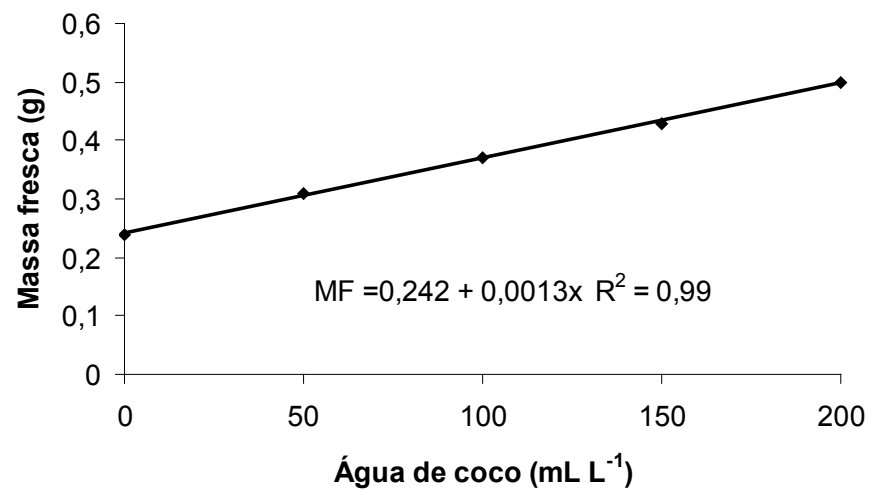

Figura 3. Valores estimados da massa fresca (MF) de plantas de D. nobile, em função dos volumes de água de coco utilizados [estimated values of fresh weight (MF) of plants of $D$. nobile, depending on the volumes of coconut water used]. Dourados, UFGD, 2010.

não promova alteração no número de plântulas e germinação (\%) de D. nobile, a adição de $200 \mathrm{~mL} \mathrm{~L}^{-1}$ de água de coco ao meio de cultura propicia os melhores resultados para comprimento de pseudobulbos, comprimento de raízes, número de raízes, número de pseudobulbos, número de folhas e massa fresca de plantas, sendo este volume recomendado para germinação assimbiótica de D. nobile.

\section{AGRADECIMENTOS}

Ao Fundect-MS pelo apoio financeiro e ao Prof. Walmes Marques Zeviani, do Depto. de Estatística da UFPR pelo auxílio na análise dos dados.

\section{REFERÊNCIAS}

ARAGÃO WM; ISBERNER IV; CRUZ EMO. 2001. Água de coco. Aracaju: Embrapa CPATC/ Tabuleiros Costeiros, Série Documentos 24. 32p.

ARAUJO AG; PASQUAL M; SILVA AB; VILLA F; ROCHA HS; COSTA FC. 2006a. Propagação in vitro de plântulas de orquídea em diferentes meios de cultura e concentrações de citocinina. Plant Cell Culture and Micropropagation 2: 68-73.

ARAUJO AG; PASQUAL M; VILLA F; COSTA FC. 2006b. Água de coco e polpa de banana no cultivo in vitro de plântulas de orquídea. Revista Ceres, 53: 608-613.

BANZATO DA; KRONKA SN. 1992. Experimentação agrícola. 2.ed. Jaboticabal: FUNEP. 247p.

BERLETH T; KROGAN NT; SCARPELLA E. 2004. Auxin signals - turning genes on and turning cells around. Current Opinion in Plant
Biology 7: 553-563.

CALDAS LS; Haridasan P; Ferreira ME. 1998. Meios nutritivos. In: TORRES AC; CALDAS LS; BUSO JA (eds). Cultura de tecidos e transformação genética de plantas. Brasília: EMBRAPA/ CNPH. p.87-132.

CAMPOS DM. 2002. Orquídeas: manual prático de cultura. 3. ed. Rio de Janeiro: Expressão e Cultura. 143p.

CAMPOS DM. 2010. Reprodução por sementes em laboratório caseiro. 1.ed. Rio de Janeiro: Expressão e Cultura. 100p.

CARDOSO JC; ONO EO. 2011. In vitro growth of Brassocattleya orchid hybrid in different concentrations of $\mathrm{KNO}_{3}, \mathrm{NH}_{4} \mathrm{NO}_{3}$ and benzylaminopurine. Horticultura Brasileira 29: 359-363.

DRONK AG. 2004. Meios de cultura e condições de luminosidade para o cultivo in vitro de Cattleya amethystoglossa Linden \& Rchib. f. Curitiba: UFPR. 30p (Tese mestrado).

FARIA RT; RODRIGUES FN; OLIVEIRA VRO; MÜLLER C. 2004. In vitro Dendrobium nobile plant growth and rooting in different sucrose concentrations. Horticultura Brasileira 22: 780-783.

FERREIRA DF. 2010. Programa de análises estatísticas (Statistical Analysis Software) e planejamento de Experimentos - SISVAR 5.3. Universidade Federal de Lavras.

GE L; YONG JWH; GOH NK; CHIA LS; TAN SN; ONG ES. 2005. Identification of kinetin and kinetin riboside in coconut (Cocus nucifera L.) water using a combined approach of liquid chromatography-tandem mass spectrometry, high performance liquid chromatography and capillary electrophoresis. Journal of Chromatography 829: 26-34.

GEORGE EF; HALL MA; DE KLERK GJ. 2008. Plant propagation by tissue culture. v. 1 The Background, $3^{\text {rd }}$ edition. Springer, Dordrecht, $501 \mathrm{p}$.

KNUDSON L. 1946. A new nutrient solution for the germination of orchid seed. American Orchid Society Bulletin, 14: 214-217.
MA Z; GE L; LEE ASY; YONG JWH; TAN SN; ONG ES. 2008. Simultaneous analysis of different classes of phytohormones in coconut (Cocus nucifera L.) water using high performance liquid chromatography and liquid chromatography-tandem mass spectrometry after solid-phase extraction. Analytica Chimica Acta 610: 274-281.

MARTÍNEZ DM; GARCÍA RAM. 2007. Efecto de los compuestos orgánicos en la propagación in vitro de Stanhopea tigrina bateman (Orchidaceae). Foresta Veracruzana 9: 27-32.

MURASHIGE T; SKOOG F. 1962. A revised medium for rapid growth and bioassays with tobacco tissue cultures. Physiologia Plantarum 15: 473-497.

NUNES CF; DALILHIA MP; SANTOS N; CUSTÓDIO TN; ARAÚJO AG. 2008. Diferentes suplementos no cultivo in vitro de embriões de pinhão-manso. Pesquisa Agropecuária Brasileira 43: 9-14.

OVERBEEK J; CONKLIN ME; BLAKESLEE AF. 1941. Factors in coconut milk essential for growth and development of very young Datura embryos. Science 94: 350-351.

PASQUAL M; FIGUEIREDO MA; REZENDE JC; ARAÚJO AG; SANTOS FC; FERREIRA EA; JUNQUEIRA KP. 2009. Fontes de nitrogênio, polpa de banana e ágar no desenvolvimento in vitro de plântulas de orquídea. Horticultura Brasileira 27: 211-216.

PASQUAL M; SOARES JDR; RODRIGUES FA; ARAUJO AG; SANTOS RR. 2011. Influência da qualidade de luz e silício no crescimento in vitro de orquídeas nativas e híbridas. Horticultura Brasileira 29: 324-329.

SANTOS AF; VENTURA GM; DIAS JMM; GOULART MS; NOVAIS RF; CECON PR; TEIXEIRA SL; MOURA E. 2006. Otimização da propagação de Sophronitis coccinea (Orchidaceae) considerando meios de cultivo com adição de carvão ativado. Horta 46: 8-12.

SIMÕES FC; PAIVA PDO; RODRIGUES TM. 1999. Efeito de diferentes meios de cultura, água de coco e carvão ativado na propagação in vitro de meristemas de Epidendrum sp. e Dendrobium sp. In 12 CONGRESSO BRASILEIRO DE FLORICULTURA E PLANTAS ORNAMENTAIS. Anais... Jaboticabal: SBFPO. p.109.

SOBIESZCZUK-NOWICKA E; WIECZOREK P; LEGOCKA J. 2009. Kinetin affects the level of chloroplast polyamines and transglutaminase activity during senescence of barley leaves. Acta Biochimica Polonica 56: 255-259.

VENTURA GM; DIAS JMM; TEIXEIRA LS; CARVALHOS SV; MOTOIKE YS; NOVAIS FR; CECON RP. 2002. Organogênese in vitro a partir de gemas apicais e axilares de plantas adultas de orquídeas do grupo Cattleya. Revista Ceres 47: 613-628.

VIEIRA JGZ; UNEMOTO LK; YAMAKAMI JK; NAGASHIMA GT; FARIA RT; AGUIAR RS. 2009. Propagação in vitro e aclimatização de um híbrido de Cattleya Lindl. (Orchidaceae) utilizando polpa de banana e água de coco. Cientifica 37: 48-52. 